\title{
Caregivers' Perception of Unintentional Child and Adolescent Injuries in Enugu, Nigeria
}

\author{
Christopher B. Eke, Obianuju O. Igbokwe, Vivian 0. Onukwuli* \\ Department of Paediatrics, College of Medicine, University of Nigeria Enugu Campus/University of Nigeria Teaching Hospital, \\ Ituku/Ozalla, Enugu \\ Email: Christopher.eke@unn.edu.ng, obianuju.igbokwe@unn.edu.ng, *vivian.onukwuli@unn.edu.ng
}

How to cite this paper: Eke, C.B., Igbokwe, O.O. and Onukwuli, V.O. (2019) Caregivers' Perception of Unintentional Child and Adolescent Injuries in Enugu, Nigeria. Open Journal of Pediatrics, 9, 218-231.

https://doi.org/10.4236/ojped.2019.93021

Received: June 4, 2019

Accepted: August 19, 2019

Published: August 22, 2019

Copyright (๑) 2019 by author(s) and Scientific Research Publishing Inc. This work is licensed under the Creative Commons Attribution International License (CC BY 4.0).

http://creativecommons.org/licenses/by/4.0/

\begin{abstract}
Background: Injury is an increasing cause of childhood morbidity and mortality globally. Purpose: The objective of the study was to evaluate caregivers' perception of unintentional child and adolescent injuries in Enugu. Methods: This was a cross-sectional descriptive study. Data were collected from caregivers of children attending the children's outpatients' unit of the hospital during the period of the study, who were selected consecutively using semi-structured interviewer administered questionnaire. Data were analysed using SPSS version 20.0. The level of statistical significance was set at $p<0.05$. Results: A total of 728 caregiver-child pairs were interviewed, out of which 526 (72.3\%) recalled history of injuries in their wards within the past 12 months. Most of the injuries occurred at home (334; 63.5\%), in males $329(62.5 \%)$, and in the 1 - 4 years age group 239 (45.4\%). On further analysis, age of the child, male sex, residence in rural area and stage of child's development significantly predicted the risk of having an unintentional injury. Majority of the interviewees had heard of first aid (432; 59.3\%) though only a few 23 (5.4\%) actually owned well equipped first aid boxes. Most of the respondents felt that injuries in children were preventable, 429 (58.9\%). However, a good number agreed that they needed clear education on preventive measures of childhood injuries, 485 (66.6\%). Conclusion: Unintentional injuries occur commonly in children and are largely preventable. Appropriate health and environmental education is needed to reduce the rising incidence of injuries in children in our setting.
\end{abstract}

\section{Keywords}

Childhood Injuries, Caregivers' Perception, Nigeria

\section{Introduction}

Childhood injuries are an increasing global public health burden. With im- 
proved and widespread global immunization strategies for various childhood killer infectious diseases, injuries are now reported as the world's leading cause of morbidity and mortality in children [1] [2]. Nearly 950,000 children under the age of 18 years die annually from injury or violence [2] [3]. It has been reported that 90 percent of these deaths amounting to about 830, 000 cases are as a result of unintentional injuries and this equals the number of children dying from complications of some common vaccine-preventable diseases including measles, diphtheria, polio, whooping cough and tetanus combined [4].

Domestic injuries including cuts, falls, burns, poisoning, animal/insect bites; injuries occurring at school, workplace injuries, injuries due to war and conflict including insurgency, and child abuse contribute to the total burden of injuries among children [1] [3], with majority occurring at home [5] [6].

Majority of these injuries occurring in children are due to unintentional mechanisms [1] and these injuries pose a big threat to child health, with causing significant economic, psychological burden and loss to the affected families and the nation at large [7].

In addition to mortality arising from these childhood injuries, millions of affected children often require hospitalization for care of non-fatal cases, with many left with various forms of disability and/or chronic pain, [8] which limit their performance of daily activities [8].

It has been reported that cases of childhood injuries particularly road traffic crashes and falls constitute the leading causes for Disability-Adjusted Life Years (DALYS) lost for children [9].

In many African countries including Nigeria, injuries rank among the top common contributors of child and adolescent mortality [10] [11] [12] [13] [14].

Evidence suggests that majority of childhood injuries are largely preventable following implementation of effective intervention models [8].

Countries that have recorded remarkable achievements in child and adolescent injury prevention have put in place a combination of multi-sectoral policies and programme to reduce childhood injuries among their population. These include legislation and enforcement, product modification, environmental modification, home visitation, safety devices, continued education, care and rehabilitation of injured children among others [4].

The World health organization and the United Nation's Children Fund and other governmental and non-governmental organizations have been in the forefront of providing policies, guidelines, training and support with regards to prevention of childhood injuries globally [15] [16]. With about 98 percent of unintentional childhood injuries reported from low and middle- income countries [17], who are still grappling with severe infrastructural and human capacity deficits, there is urgent need to determine the pattern and determinants of childhood injuries in our setting.

There is paucity of national epidemiological data on the magnitude of childhood injuries including fatal and non-fatal cases in our setting, with many seek- 
ing care from informal medical care including patent medicine vendors/dealers and traditional healers leaving only a few especially the severely injured presenting to hospitals [12].

Hence the objective of the current study was to determine the caregivers' perception of unintentional child and adolescent injuries in Enugu, Nigeria.

\section{Methods}

\subsection{Study Setting}

This study was conducted at the children's Outpatient Unit of the Department of Paediatrics, University of Nigeria Teaching Hospital (UNTH), Ituku-Ozalla, Enugu, Nigeria.

UNTH is a 750-bed capacity tertiary hospital situated at Ituku-Ozalla in Enugu State Southeast Nigeria. About one hundred and twenty children are seen in the outpatient department of the hospital on each working day Mondays through Fridays.

\subsection{Study Design}

This was a cross sectional descriptive study involving caregivers' of children attending the children's outpatient Unit of the Department of Paediatrics, UNTH, Ituku-Ozalla, Enugu, Nigeria.

\subsection{Ethical Concerns}

Study ethical approval was sought and obtained from the Health Research and Ethics Committee of University of Nigeria Teaching Hospital, Enugu (NHREC/ 05/01/2008B-FWA00002458-IRB00002323). Informed written consent was also obtained from all the respondents prior to recruitment into the study.

\subsection{Inclusion Criteria}

Respondents were caregivers of children including those whose child/children may or may not have sustained injuries previously and attending the children's outpatients' unit of the hospital during the period of the study. They gave their informed written consent and were consecutively recruited into the study.

\subsection{Exclusion Criteria}

Caregivers who did not give their consent for the study were not recruited.

\subsection{Questionnaire Design}

The study was undertaken using a semi-structured interviewer-administered pre-tested questionnaire designed for the study which was adapted from similar previous studies [12] [18].

\subsection{Conduct of the Study}

The study was conducted from 1st February to 31st March, 2019. The designed 
questionnaire was pre-tested among mothers attending the children's outpatient unit and the content found to be unambiguous prior to the commencement of the study.

The respondents selected for the pre-test were excluded from the actual study.

The questionnaire sought to determine the socio-demographic characteristics of the respondents including age of caregiver, child's age in years and sex, place of residence, highest educational attainments and occupations of the parents from which the social class was determined. Others include the caregivers views on basic risk factors for childhood injuries (age of child, sex of child, child's stage of development, illness of the caregiver, child visiting a new environment), characterization and outcome of unintentional injuries in children (history of injury in the child, type of injury sustained, anatomic part of the body involved and its severity), treatment given with outcome of the injuries among the children as well as knowledge and usage of first aid box among caregivers.

\subsection{Social Class Determination}

The social class of each child was determined using the method advanced by Oyedeji [17] among a population of Nigerian children. Here, the social class of each child was obtained with the highest educational attainment and occupation of the mother and father combined. The average of the four scores (two each for the father and mother respectively, that is, occupational status and highest educational attainment) to the nearest whole number was assumed as the social class of each child studied. The highest score is 1 while the lowest is 5 . Social classes I and II; III; IV and V were classified as high, middle, and low socioeconomic class respectively. In the situation where one of the parents is late, the social class of the child is then determined using only that of the surviving parent.

Definition of term: Child unintentional injury: is a non-purposeful damage or physical trauma occurring in a child [1].

\subsection{Data Analysis}

The data were analysed using statistical package for social sciences (SPSS) version 20.0 Chicago Il. The level of statistical significance was set at $\mathrm{p}<0.05$.

\section{Results}

A total of 728 caregiver-child pairs were interviewed. Of these, 371 (51\%) were males, while 357 (49\%) were females. The mean age of the children was $5.9 \pm 4.37$ years, while the mean age of the caregivers (mothers) was $33.96 \pm 6.73$ years.

Majority of the respondents resided in apartments and public yards (505; $69.4 \%$ ) while the rest resided in private houses $(187 ; 25.7 \%)$. Also, most of the interviewees resided in rural areas 378 (51.9\%) while 350 (48.1\%) lived in urban locations as shown in Table 1.

All the caregivers studied were mothers and 98 (13.4\%) of them had either no formal education or primary education as their highest educational level whilst 
$630(86.5 \%)$ had secondary education and higher.

A greater number of the respondents were of the working class, either civil servants $(239 ; 32.8 \%)$, self-employed $(294 ; 40.4 \%)$ or privately employed (8; $1.1 \%)$ while 187 (25.7) of them were unemployed. Majority of the respondents were of lower socio-economic class (482; 66.2\%). See Table 1.

Of the 728 respondents, $526(72.3 \%)$ recalled history of injuries in their children/wards within the past 12 months and about a quarter reported that a child was injured more than once. Most of these injuries occurred at home (334; $63.5 \%)$, while the rest occurred at school, along the road and in the neighbourhood $(184 ; 35.9 \%)$.

Of the children reported to be injured, 329 (62.5\%) were males while 197 (37.5\%) being females.

Table 1. Socio-demographic characteristics of caregivers and their children pairs.

\begin{tabular}{|c|c|c|}
\hline Features & Frequency $N=728$ & $\mathrm{~N} \%$ \\
\hline \multicolumn{3}{|l|}{ Sex } \\
\hline Male & 357 & 49.0 \\
\hline Female & 371 & 51.0 \\
\hline \multicolumn{3}{|l|}{ Place of Residence } \\
\hline Rural & 378 & 51.9 \\
\hline Urban & 350 & 48.1 \\
\hline \multicolumn{3}{|l|}{ Maternal Education } \\
\hline No Formal Education & 12 & 1.6 \\
\hline Primary & 86 & 11.8 \\
\hline Secondary & 230 & 31.6 \\
\hline Diploma & 129 & 17.7 \\
\hline Degree & 271 & 37.2 \\
\hline \multicolumn{3}{|l|}{ Maternal Occupation } \\
\hline Housewife/Unemployed & 187 & 25.7 \\
\hline Self-Employed & 294 & 40.4 \\
\hline Privately Employed & 8 & 1.1 \\
\hline Government Employee & 239 & 32.8 \\
\hline \multicolumn{3}{|l|}{ Social Class } \\
\hline 1 & 8 & 1.1 \\
\hline 2 & 43 & 5.9 \\
\hline 3 & 195 & 26.8 \\
\hline 4 & 325 & 44.6 \\
\hline 5 & 157 & 21.6 \\
\hline Mean Age of Children (in Years) & $5.96 \pm 4.37$ & \\
\hline Mean Age of Mother (in Years) & $33.96 \pm 6.73$ & \\
\hline
\end{tabular}


The injury occurred mainly in the 1 - 4 years age bracket 239 (45.4\%) followed by the 5 - 9 years $164(31.2 \%), 10$ - 18 years $65(12.4 \%)$ and infants $58(11.0 \%)$ respectively.

The most important risk factors for injuries were age of the child 624 (85.7\%), sex of the child 589 (80.9\%), child's stage of development $526(72.3 \%)$. Other risk factors were nature/location of residence 457 (62.8\%), climbing of heights $129(17.7 \%)$ and overactivity $92(12.6 \%)$ as shown in Table 2.

Falls were the commonest cause of these injuries $(362 ; 68.8 \%)$, followed by cuts/lacerations (87; $16.5 \%)$, burns $(30 ; 5.7 \%)$ and road traffic crashes $(27 ; 5.1 \%)$ as shown in Table 3.

The limbs (lower limbs) were commonly affected (288; 54.8\%), followed by the head and neck $(140 ; 26.6 \%)$. In 63 of the cases, multiple sites were affected (12\%). Chest and abdominal injuries were also seen in 35 (6.6\%) of the cases. See Table 3.

On further statistical analysis using bivariate analysis the age, male sex, resident in rural area and the child's stage of development significantly predicted the risk of a child having an unintentional injury as shown in Table 4.

Majority of the interviewed caregivers had heard of first aid box (432; 59.3\%) and their main source of information was from health workers (297; 69.2\%). However, only 23 (5.4\%) actually owned well equipped first aid box and used it (see Table 5).

The observed sources of treatment for these injuries were at home (199; $37.8 \%)$, and in 80 of the cases (15.2\%) no treatment was administered. Some of the respondents patronized traditional and patent medicine vendors (92; 17.4\%), while 155 (28.9\%) visited hospital and primary health centres.

Of those that visited the hospital, 58 (11\%) were hospitalized for non-fatal injuries and of these, $50(86.2 \%)$ were treated and discharged without disability, 3 (5.2\%) recovered with disability while $5(8.6 \%)$ died as a result of the injuries. The disabilities recorded were above knee amputation of a leg, 2 (66.7\%) and chronic pain, 1 (33.3\%) as shown in Table 6.

Table 2. Caregivers views on basic risk factors of childhood injuries*

\begin{tabular}{ccc}
\hline Characteristic & Frequency $(\mathbf{N}=\mathbf{7 2 8})$ & Percent (\%) \\
\hline Age of Child & 624 & 85.7 \\
Sex of Child & 589 & 80.9 \\
Stage of Development & 526 & 72.3 \\
Nature/Location of Residence & 457 & 62.8 \\
Climbing of Heights & 129 & 17.7 \\
Overactivity & 105 & 14.4 \\
Illness of Caregiver/s & 92 & 12.6 \\
Change of Environment & 63 & 8.7 \\
\hline
\end{tabular}

${ }^{*}$ Multiple entries allowed. 
Table 3. Characterization and outcome of unintentional injuries in children.

\begin{tabular}{|c|c|c|}
\hline Features & Frequency $(N=728)$ & Percent (\%) \\
\hline \multicolumn{3}{|l|}{ History of Injury: } \\
\hline Yes & 526 & 72.3 \\
\hline No & 202 & 27.7 \\
\hline \multicolumn{3}{|c|}{ Place of Occurrence $(n=526)$} \\
\hline Home & 334 & 63.5 \\
\hline School & 99 & 18.8 \\
\hline Neighbourhood & 57 & 10.8 \\
\hline Roadways & 28 & 5.3 \\
\hline Others & 8 & 1.5 \\
\hline \multicolumn{3}{|l|}{ Cause of Injury $(n=526)$ : } \\
\hline Falls & 362 & 68.8 \\
\hline Cuts/Lacerations & 87 & 16.5 \\
\hline Burns & 30 & 5.7 \\
\hline Road Traffic Accidents & 27 & 5.1 \\
\hline Poisoning & 8 & 1.5 \\
\hline Fractures & 4 & 0.8 \\
\hline Electrocution & 4 & 0.8 \\
\hline Drowning & 3 & 0.6 \\
\hline Foreign Body Aspiration & 1 & 0.2 \\
\hline \multicolumn{3}{|c|}{ Anatomic Region Affected $(n=526)$ : } \\
\hline Limbs & 288 & 54.8 \\
\hline Head and Neck & 140 & 26.6 \\
\hline Multiple Sites & 63 & 12.0 \\
\hline Chest Injury & 27 & 5.1 \\
\hline Abdominal Injury & 8 & 1.5 \\
\hline
\end{tabular}

Table 4. Bivariate analysis of the risk factors of childhood injuries.

\begin{tabular}{ccc}
\hline Risk Factors & Correlation Coefficient & p-Value \\
Age & -1.293 & $0.009^{*}$ \\
Sex & 0.596 & $0.043^{*}$ \\
Place of Residence & 0.623 & $0.039^{*}$ \\
Maternal Education & -0.080 & 0.835 \\
Social Class & 0.007 & 0.978 \\
Child's Stage of Development & 0.401 & $0.047^{*}$
\end{tabular}


Table 5. Caregivers perception and usage of first aid box.

\begin{tabular}{ccc}
\hline Features & Frequency $(\mathbf{N}=\mathbf{7 2 8})$ & Percent (\%) \\
\hline Heard of First Aid Box $(\mathbf{n}=\mathbf{7 2 8}):$ & 296 & 40.7 \\
No & 432 & 59.3 \\
Yes & $(\mathrm{n}=429)$ & \\
Source of Information: & 297 & 69.2 \\
Health Workers & 89 & 20.7 \\
Friends/Relations & 43 & 10.0 \\
Media & $(\mathrm{n}=429)$ & \\
Ownership of Well-Equipped First Aid Box: & 23 & 5.4 \\
Yes & 406 & 94.6 \\
No &
\end{tabular}

Table 6. Treatment and outcome of physical injuries among the children.

\begin{tabular}{ccc}
\hline Features & Frequency $(\mathbf{N}=\mathbf{7 2 8})$ & Percent (\%) \\
\hline Source of Treatment $(\mathbf{n}=\mathbf{5 2 6})$ : & 199 & 37.8 \\
Home Treatment & 130 & 24.1 \\
Hospital (Public/Private) & 80 & 15.2 \\
No Treatment Given & 76 & 14.4 \\
Patent Medicine Vendors & 25 & 4.8 \\
Primary Health Centre & 16 & 3.0 \\
Traditional Healer & & \\
Need for Hospitalization: & 58 & 11.0 \\
Yes & 468 & 89.0 \\
No & & 8.6 \\
Outcome of Injury in Hospitalized Children $(\mathbf{n}=58):$ & 50 & 86.2 \\
Treated and Discharged without Disability & 3 & $5.2^{\star}$ \\
Recovered with Disability & 5 & 8.6 \\
Demised & &
\end{tabular}

*Pattern of disability: above knee amputation of a leg 2 (66.7\%); chronic pain, 1 (33.3\%).

Majority of the respondents are of the opinion that injuries in children are preventable, $429(58.9 \%)$. Also, most of the caregivers felt that they needed clear education about preventive measures of paediatric injuries, 485 (66.6\%) whereas 243 (33.4\%) felt that most child injuries are destined to happen by nature.

\section{Discussion}

Injuries have been reported as one of the leading causes of morbidity and mortality in children and adolescents globally [2]. The current study has explored caregivers' perception of unintentional injuries in children in our setting. 
Majority of the respondents who are mothers of the children involved in the injuries actually understood the actual meaning of childhood unintentional injury.

A staggering high number of the interviewees recalled different forms of injuries in their wards in the last 12 months occurring once or more times. A similar finding was reported by Abdur-Rahman et al. [12] in a community survey of childhood injuries in North-Central region of Nigeria.

From the study the major determinants risk factors for injuries in a child were the age, male sex, being resident in a rural area, and child's stage of development as corroborated by other workers [1] [10] [20].

Age was a determinant factor of injuries among the study population with most occurring in children between the ages 1 to 4 years. Most children between toddlerhood and preschool age tend to be exploring the environment as well as trying new games and climbing heights hence chances are that these groups of children are more predisposed to having injuries as observed in the current study and similar researches [12].

The males also tended to be more involved in injuries as equally observed in the current study cohort. The boys were more autonomous and it is possible that the male gender specific impulsive behavior such as rough play and taking risks including getting involved in dangerous games are believed to account for more males to be involved in different forms of injuries. This has been corroborated by other workers [2] [19] [20] [21].

Domestic environment could play a significant role particularly in-home accidents [5], and poisoning [5]. In the current study, the nature/place of residence significantly determined a child's proneness to injury as most of the injuries occurred in children living in rural areas with possibility of overcrowding and lack of safety devices in the households. A child health and injury survey in Bangladesh showed that children living in homes with exposed wires in the houses who were mostly rural dwellers tend to have more mortality following electrocution [22]. Similar studies have posited that children resident in rural areas tended to be of lower socioeconomic background with increased likelihood of poor environmental infrastructure and as such more exposed to injuries as seen in the present study [23] [24].

Studies have alluded to the fact that the stage of child's development significantly determines the chances of sustaining/being involved in an injury as children are not generally aware of the risks and consequences of the common injuries [3], particularly when taking risks.

Majority of the caregivers in the present study were mothers with at least secondary education. However maternal education did not significantly predict the risk of childhood injury (correlation coefficient, $r$ : -0.080 ; p-value 0.835 ) which is at variance to findings in other studies that observed that higher parental education correlates with lower incidence of childhood injury [25] [26].

Falls ranked the most common cause of injury in the current study followed by cuts/lacerations, road traffic injuries and burns. A similar pattern of uninten- 
tional child injuries have been observed in different childhood populations [3] [27] [28] [29].

Most of the injuries reported affected the limbs particularly the lower limbs as have been observed in similar studies [12].

Among the study population who had sustained one type of injury or the other, $11 \%$ (58) of them needed hospitalization for continued care out of which seven died (12.1\%) as reported by the respondents. However, it was observed that a significant number still patronize patent medicine vendors and traditional healers including native bone setters who may not be well trained to assess injured patients to determine those that needed specialized care or even manage them adequately thus increasing the risk of morbidity and mortality in them.

Some local hospital studies [30] [31], on childhood injuries have shown the pattern and outcome of children with injuries including hospitalization rates and many reporting high mortality rates. Late presentation possibly arising from patronization of traditional healers, patent medicine vendors and poverty could account for some of the high mortality rates in some of the studies in our locale including the current study [30] [31] [32] [33].

A non-fatal injury in children is an increasing cause of morbidity in children particularly those between one to four years with many having lifelong disabilities or chronic pain that may impact negatively on performance of daily activities. [8] Three (5.2\%) of the $58(100.0 \%)$ hospitalized children in the current study recovered with different disabilities ranging from amputation of the legs and mal-union. Also, most disabilities occurring in early life tend to impact on the child's overall growth and development including self-care, mobility, psychosocial functioning [3], in addition to the resulting huge economic burden both on the families and the government health budget [34].

Generally non-fatal injuries could impact negatively on productivity and economic cost and in some cases ownership and use of appropriate first aid could improve the outcome of the injury when applied early and may help to save lives [35], particularly in those living in remote areas where most of these injuries occur [23] [24]. Such a first aid could be applied to the injured while efforts are being made to transfer the wounded to the referral hospital. The International Federation of Red Cross and Red Crescent (IFRC) states that though first aid is not a substitute for emergency health services, it is a key primary strategy for providing effective and rapid interventions to reduce severe injuries and improve survival [35]. Observation in the current study showed that though a substantial number of the interviewees have heard of first aid box only a fraction of them actually owned a well-equipped first aid box and used it. Hence, to obtain the desired outcome following the use of first aid it should be instituted immediately following the occurrence of an injury.

From the current study majority of the respondents are of the opinion that childhood unintentional injuries are largely preventable, however clear and specific health education is needed in order to stern the tide of this challenging sit- 
uation. The World Health Organization (WHO) has recommended a set of preventive measures covering legislation, regulations by the national governments, changes of environmental education and emergency medical care. These emergency care as being pushed by the WHO is the Emergency and Trauma CareWHO Global Alliance for care of the injured (GACI) and is aimed at saving millions of lives and minimizing the consequences of injuries by strengthening trauma care systems. Also other similar efforts to improve care of the multiple injured include the training on advanced/ Paediatric life support (APLS).

Comprehensive Paediatric guidelines on the management of the multiply injured child are still lacking in most countries in sub-Saharan Africa. Hence there is a need for articulation of regional and national guidelines for emergency medical care of the multiple injured in our setting.

Appropriate health and environmental education, targeted government policies, legislation and institution of standardized emergency and trauma care for the multiple injured is needed to stern the tide of childhood injuries in our setting.

\section{Funding}

The study was completely funded by the authors. No institutional or other funding obtained for the study.

\section{Conflicts of Interest}

The authors declare no conflicts of interest regarding the publication of this paper.

\section{References}

[1] Sleet, D.A. (2018) The Global Challenge of Child Injury Prevention. International Journal of Environmental Research and Public Health, 15, 1921. https://doi.org/10.3390/ijerph15091921

[2] Jildeh, C., Abdeen, Z., Al Sabbah, H. and Philalithis, A. (2013) Unintentional Injuries among School Aged Children in Palestine: Findings from the National Study of Palestinian School Children (HBSC-WBG 2006). International Journal of Population Research, 2013, Article ID: 629159. https://doi.org/10.1155/2013/629159

[3] Hemalatha, K. and Prabhakar, V.R. (2018) Prevalence of Childhood Injuries-A Survey of Injury of Epidemiology in Rural Population of Tamil Nadu, India. Journal of Medical Society, 32, 27-32. https://doi.org/10.4103/jms.jms_7_17

[4] Harvey, A., Towner, E., Peden, M., Soori, H. and Bartolomeos, K. (2009) Injury Prevention and the Attainment of Child and Adolescent Health. Bulletin of the World Health Organization, 87, 390-394. https://doi.org/10.2471/BLT.08.059808

[5] Da Silva, M.E., da Silva Fontinele, D.R., de Oliveira, A.V.S., Bezerra, M.A.R. and da Rocha, S.S. (2017) Determining Factors of Domestic Accidents in Early Childhood. Journal of Human Growth and Development, 27, 10-18. https://doi.org/10.7322/jhgd.127643

[6] Ablenhit, J., Peel, I., McDaid, L., Hawkins, A., Goodenough, T., Deave, T., et al. (2015) Parental Perceptions of Barriers and Facilitators to Preventing Child Unintentional Injuries within the Home: A Qualitative Study. BMC Public Health, 15, 
280. https://doi.org/10.1186/s12889-015-1547-2

[7] Polinder, S., Haagsma, J.A., Toet, H., Brgmans, M.J., van Beek, E.F. and the EUROCOST and APOLLO Reference Groups (2010) Burden of Injury in Childhood and Adolescence in 8 European Countries. BMC Public Health, 10, 45. https://doi.org/10.1186/1471-2458-10-45

[8] Fang, Y., Zhang, X., Chen, W., Lin, F., Yuan, M., Grng, Z., et al. (2015) Epidemiological Characteristics and Burden of Childhood and Adolescent Injuries: A Survey of Elementary and Secondary Students in Xiamen, China. BMC Public Health, 15, 357. https://doi.org/10.1186/s12889-015-1726-1

[9] Peden, M., Oyegbite, K., Ozanne-Smith, J., et al. (2008) World Report on Child Injury Prevention. World Health Organization, Geneva.

[10] Kobusingye, O., Guwatudde, D. and Lett, R. (2001) Injury Patterns in Rural and Urban Uganda. Injury Prevention, 7, 46-50. https://doi.org/10.1136/ip.7.1.46

[11] Mutto, M., Lawoko, S., Nansamba, C., Ovga, E. and Svanstron, L. (2011) Unintentional Childhood Injury Patterns, Odds, and Outcomes in Kampala City: An Analysis of Surveillance Data from the National Emergency Unit. Journal of Injury and Violence Research, 3, 13-18. https://doi.org/10.5249/jivr.v3i1.56

[12] Abdur-Rahman, L.O., Taiwo, J.O., Ofoegbu, C.K.P., Adekanye, A.O., Ajide, O.O., Ijagbemi, C.Y., et al. (2015) Community Survey of Childhood Injuries in North-Central, Nigeria. Annals of Pediatric Surgery, 11, 136-139. https://doi.org/10.1097/01.XPS.0000462928.45595.53

[13] Adesunkanmi, A.R., Oginni, L.M., Oyela, A.O. and Badru, O.S. (1998) Epidemiology of Childhood Injury. The Journal of Trauma, 44, 506-512. https://doi.org/10.1097/00005373-199803000-00015

[14] Solagberu, B.A. (2002) Trauma Deaths in Children: A Preliminary Report. Nigerian Journal of Surgical Research, 4, 99-102. https://doi.org/10.4314/njsr.v4i3.12157

[15] Malta, D.C., do Prado, R.R., da Silva, M.M., da Silva Junior, J.B. and de Souza Minayo, M.C. (2014) Factors Associated with Injuries in Adolescents, from the $\mathrm{Na}$ tional Adolescent School-Based Health Survey (PeNSE 2012). Revista Brasileira de Epidemiologia, 17, 183-202. https://doi.org/10.1590/1809-4503201400050015

[16] World Health Assembly Resolution 60.22. http://wwww.who.int/gb/ebwha/pdf-files/WHA60/A60R22-en.pdf

[17] WHO Trauma and Services Publications and Resources. http://www.who.int/violence_injury_prevention?publications/services/en/index.ht $\underline{\mathrm{ml}}$

[18] Oyedeji, G.A. (1985) Socio-Economic and Cultural Background of Hospitalized Children in Ilesha. Nigerian Journal of Paediatrics, 12, 111-117.

[19] Mayhre, M.C., Thoresen, S., Grogaard, J.B. and Dyb, G. (2012) Familial Factors and Child Characteristics as Predictors of Injuries in Toddlers: A Prospective Cohort Study. BMJ Open, 2, e000740. https://doi.org/10.1136/bmjopen-2011-000740

[20] Tiruneh, B.T., Tesfaye, B.B., Ankay, D.Z., Yismaw, Y.S., Tesfaye, E. and Dachew, B.A. (2017) Factors Associated with Unintentional Injury among the Paediatric Age Population in the Hospitals of Amhara National Regional State, Ethiopia. African Journal of Emergency Medicine, 7, 555-559.

https://doi.org/10.1016/j.afjem.2017.08.008

[21] Ugezu, A.I., Ihegihu, C.C., Chukwuka, N.C., Ndukwu, C.U. and Ofiaeli, R.O. (2017) Childhood Injuries in a Teaching Hospital Setting, Nnewi, South-East Nigeria. Tropical Journal of Medical Research, 20, 171-174. 
https://doi.org/10.4103/tjmr.tjmr_6_17

[22] Chowdhurg, S.M., Rahman, A., mashreky, S.R., Giashuddin, S.M., Svanstrom, L. and Rohman, F. (2009) The Horizon of Unintentional Injuries among Children in Low-Income Setting-An Overview from Bangladesh Health and Injury Survey. Journal of Environmental and Public Health, 2009, Article ID: 435403. https://doi.org/10.1155/2009/435403

[23] Gilbride, S.J., Wild, C., Wilson, D.R., Svenson, L.W. and Spady, D.W. (2018) Socio-Economic Status and Types of Childhood Injury in Alberta: A Population Based Study. BMC Pediatrics, 6, 30. https://doi.org/10.1186/1471-2431-6-30

[24] Morrow, V., Burnet, I. and Vujcich, D. (2014) Understanding the Causes and Consequences of Injuries to Adolescents Growing in Poverty in Ethiopia, Andhra Pradesh (India), Vietnam and Peru: A Mixed Method Study. Health Policy and Planning, 29, 67-75. https://doi.org/10.1093/heapol/czs134

[25] Myhre, M.C., Thoresen, S., Grogaard, J.B. and Dyb, G. (2012) Familial Factors and Child Characteristics as Predictors of Injuries in Toddlers: A Prospective Cohort Study. BMJ Open, 2, e000740. https://doi.org/10.1136/bmjopen-2011-000740

[26] Delgado, J., Ramlrez-Cardich, M.E., Gilman, R.H., Lavarello, R., dahodwala, N., Bazan, A., et al. (2002) Risk Factors for Burns in Children: Crowding, Poverty, and Poor Maternal Education. Injury Prevention, 8, 38-41.

https://doi.org/10.1136/ip.8.1.38

[27] Vas, A.S. and Dhai, A. (2017) Childhood Injuries: A Commission for Human Responsibilities Is Needed. South African Medical Journal, 107, 180-181. https://doi.org/10.7196/SAMJ.2017.v107i3.12251

[28] Jonkheijm, A., Johanna, J., Zuidgeest, H., van Dijk, M. and van As, A. (2013) Childhood Unintentional Injuries: Supervision and First Aid Provided. African Journal of Paediatric Surgery, 10, 339-344. https://doi.org/10.4103/0189-6725.125446

[29] Ekwunife, O.H., Ugwu, J.O., Modekwe, V., Okoli, C.C. and Ugezi, A. (2015) Epidemiology of Admitted Cases of Childhood Injuries in Nnamdi Azikiwe University Teaching Hospital, Nnewi, Nigeria. Annals of Tropical Medicine and Public Health, 8, 272-275. https://doi.org/10.4103/1755-6783.162642

[30] Ekenze, S.O., Anyanwu, K.K. and Chukwumam, D.O. (2009) Childhood Trauma in Owerri (South Eastern) Nigeria. Nigerian Journal of Medicine, 18, 79-83.

[31] Adeboye, M.A., Ojuawo, A., Ernest, S.K., Fadeyi, A. and Salisu, O.T. (2010) Mortality Pattern within 24 Hours of Emergency Paediatric Admission in a Resource-Poor Nation Health Facility. West African Journal of Medicine, 29, 249-252. https://doi.org/10.4314/wajm.v29i4.68245

[32] Adegoke, S.A., Dedeke, I.O. and Oyelami, O.A. (2010) Childhood Injuries in Ilesha, South-Western Nigeria: Causes, Pattern, and Outcome. West African Journal of Medicine, 29, 253-258.

[33] Esigbe, E.E., Anyiam, O.J., Ogunrinde, G.O., Wammanda, R.D. and Zoaka, H.A. (2012) Health Care Seeking Behavior among Caregivers of Sick Children Who Had Cerebral Malaria in Northwestern Nigeria. Malaria Research and Treatment, 2012, Article ID: 954975. https://doi.org/10.1155/2012/954975

[34] Alonge, O. and Hyder, A.A. (2014) Reducing the Global Burden of Childhood Unintentional Injuries. Archives of Disease in Childhood, 99, 62-69. https://doi.org/10.1136/archdischild-2013-304177

[35] Hoque, D.M.E., Islam, M.I., Salam, S.S., Rahman, Q.S., Agrawal, P., Rahman, A., et 
al. (2017) Impact of First Aid in Treatment Outcomes for Non-Fatal Injuries in Rural Bangladesh: Findings from an Injury and Demographic Census. International Journal of Environmental Research and Public Health, 14, 762.

https://doi.org/10.3390/ijerph14070762 